International Journal on Integrating Technology in Education (IJITE) Vol.5,No.1,March 2016

\title{
GENERAL IMPACTS OF INTEGRATING ADVANCED AND MODERN TECHNOLOGIES ON TEACHINg ENGLISH As A FOREIGN LANGUAGE
}

\author{
Minoo Alemi Ph.D \\ Assistant Professor, Islamic Azad University,Tehran-west Branch and \\ Research Associate, Social \& Cognitive Robotics Laboratory, \\ Sharif University of Technology, Tehran, Iran
}

\begin{abstract}
Technology has always played a key role in General and ESP (English for Specific Purposes)language learning and teaching. Currently the range of technologies being used in classrooms all over the globe for Language Learning and Teaching (LLT) has become very diverse, and some which have become central to language practice are briefly described in this paper. Since English is the most commonly 'learned' and 'taught' second/foreign language around the world, this paper intends to explore how advanced and modern technologies are used to support the process of English language teaching and learning for those at various stages of education. Furthermore, it presents and compares some of the innovative and novel approaches that are being explored and applied in order to improve methods of English language development and satisfy the current needs of the young generation in a highly competitive world.
\end{abstract}

\section{KEYWORDS}

Teaching English, technology, foreign language, computer, mobile phones, social robots

\section{INTRODUCTION}

With the new generation of pupils having grown up in a modern and digital era, the use of up-todate technologies in various forms for primary English language teaching and learning has gradually become a common practice around the world. Furthermore, it is well clear that technology continues to play a significant role in the development and improvement of our societies. Therefore, it also seems essential and expected to utilize modern and immerging technologies to facilitate the task of English language education. From Information and Communication Technologies (ICT) to intelligent/smart devices and robots, technology has been used in recent years to enhance second language teaching and acquisition in classrooms[114].Clearly, students trying to learn and enrich their proficiency in English as a second language need supplementary language support. To expand their knowledge, skills and experience, they must actively get engaged and practice in listening, reading, speaking, and writing. To accomplish these tasks, it is essential to use various tools and techniques which can efficiently assist them to soundly learn English language. Using modern technologies for English language teaching and learning does not seem to be restricted to any particular age group. This is confirmed by the range of examples presented here which suggest that practitioners are progressively using various forms of technologies innovatively within the early years. The term

DOI :10.5121/ijite.2016.5102 
new or emerging technology includes communication techniques for language teaching in which the internet, personal computers, social and cognitive robots, intelligent machines, and smart mobile devices play a key role. Each technical tool and device has its own advantage and application conforming to one of the four language skills (reading, speaking, listening, and writing). However, in order to use these techniques successfully, both the ESL/EFL students and instructors should be familiar with using computers, the internet, intelligent social and cognitive robots and devices, and be capable of successfully interacting with them.

In addition to the instructor's role, the effect of technology has become enormous in teaching and learning English language. In fact, one can suggest that the role of instructor along with that of technology has led to advanced learning models in second language teaching and acquisition. In many circumstances, it has been noticed that very young learners were exposed to a variety of technologies from an early age at home. As a result, by the time they reach kindergarten age many have developed at least some of the digital skills that enable them to take part in technology-driven activities as soon as they start school [2]. However, technology continues to be used for all categories of specific language teaching and learning activities, such as: oral practice, reading abilities, and writing skills progress. On the whole, ICT seems to be mostly effective when integrated into task-based language learning where English can be developed naturally through subject-oriented activities and diverse themes and areas. A typical scenario within the main part of a curriculum or lesson plan might consist of a sequence of content-driven, languagebased activities that culminate in a significant event such as an oral presentation, or a specific task like writing a letter, memo or an article. By a method termed as 'blended learning' [3], students might engage in a teacher-led question and answer session, watch a video, research using books and the internet, participate in a dialog; discussion; role play; or debate, and practice any other activities in preparation of the final assignment.

\section{BACKGROUND AND HISTORY}

Technology and English language teaching and acquisition have continuously been bonded to each other in various forms. Historically from the early 1960's to date,the use of technology has had a key role in English language learning laboratories in various educational institutions around the world. Traditional language laboratories were equipped with a number of small tables and cabinets with cassette decks, microphones, and headphones to be used by each student. Instructors used a central control panel to monitor their students' communications and performance. The main advantage of such laboratories was that spoken activities of students would assist them to quickly learn the second language. As a result, their skills would be enhanced by coming across more applied and practical day-to-day exercises. Although the language laboratory was a positive and progressive step in linking technology and language education, this technique was actually tedious and boring for many learners due to minimal interactions between the teacher and his/her students [15].

Over the past two decades, technology has found its way into the process of learning and teaching of almost all subjects and disciplines. English teachers are considered the pioneers of applying diverse modes of technology into the process of language teaching and learning. Thus, English classes and laboratories all over the world have been swiftly influenced by newly developed 
software's, local area networks, and the internet. However, this leaves teachers, material developers, and educators trying to keep up with the dramatic development of multimedia technology. With the advancement and growth of computers and mobile devices, Computer Assisted Language Learning (CALL) and Mobile Assisted Language Learning (MALL) have gained attention for second language educational theories for over fifteen years [16-20]. The use of computers in the English language classrooms and laboratories is known to be useful for both teachers and learners. Currently, there are numerous CALL software application programs available, such as: vocabulary, grammar and pronunciation programs, spell check utilities, electronic workbooks, reading/writing programs, and diverse learning packages to assist instructors in creating tutorial exercises to boost their English language courses. Times have changed, teachers have progressed, and we are now faced with new models of learning and modern technologies as teaching tools. Modern technologies such as overhead video-projectors, interactive smart whiteboards, smart telephones and iPads, tablets, laptop computers, and wireless internet have exposed the language classroom and laboratory to the real world. Teachers and lecturers who spent countless hours, days, and weeks dealing with a textbook, a tape-recorder, and a chalkboard are now proficient and adapted at using PowerPoint to present grammar, playing podcasts (digital audio files) to practice listening skills, dragging texts off the internet to present reading abilities, and possibly most ground-breaking of all; empowering students by giving them access to a wide range of web-based tools and social networks that allow them to publish work and socialize with live audiences in real settings.

This is just the beginning; as modern technological tools and devices continue to initiate new ways to improve the way that English is learned in the language laboratory, even greater changes seem to be taking place outside it, as the digital revolution progressively challenges the physical class room as a place of study. Recent investigations show that social media such as a web-based course, video conferencing, social networks, email-writing programs, and group chat room discussions can assist English language acquisition in numerous ways. This includes reducing anxiety, simplifying communication, promoting social or cooperative learning, increasing student incentive, and enabling cross-cultural consciousness. Conversely, one may possibly encounter two major difficulties in the use of the existing technologies applied in the lecture-room or language laboratory: their difficulty to customize and their incapability to interact with the learners. Since computers and mobile devices are faced with some limitations in appealing student learners and provide them with an interactive environment, possible use of other forms of technology has been explored in recent years. Among the fastest emerging technologies that have demonstrated to be of assistance to the language learning process are social robots [11-15]. From the mid-2000's social robots and interactive digital robots have also been explored as supportive and novel tools that have come to the aid of language teaching and learning, gradually evolving into the new methodology named as Robot Assisted Language Learning (RALL) [12-14].Social Robots not only have the features and interfaces already being employed in CALL and MALL, but are also capable of autonomous actions/movements, visual and voice recognition, and physical/environmental interactions when equipped with numerous sensors. While computers or mobile devices can be capable of nonverbal communication by using cyber and fake characters and/or videos, social robots are also remarkable in their capacity for nonverbal communication, such as facial expressions, gestures and actions, while coexisting with learners in a real 
environment such as home and/or classroom. Furthermore, social robots are different from computers and mobile devices in the way that they have a welcoming appearance and have the ability to be programmed for successfully keeping social relations. These new learning interventions and methodologies, clearly designates that modern and immerging technologies have much more to offer ELT, LLT, ESP, and EFL in the years to come.

\section{The ART Of LANguage LeARNing SkILls Via TeCHNOLOgY}

Teaching and learning a foreign language is known to be a fascinating art. This artistic skill applies a combination of science, culture, and geographical/environmental location to create a person with better communication competencies. The fundamental and basic skills of English language instruction and learning are: listening, reading, speaking, and writing. These skills are shown in Figure 1 in the form of input-output abilities along with their interaction with emerging technologies to affect emerging minds. Each language subject or skill requires different educational tools that best suitable to it. Utilizing various technological devices is reported to have a major impact on the learning method of each language skill [21]. The range of modern and emerging technologies being used regularly in classrooms throughout the world widely depends on the type of language skills one would wish to improve. However, as a long-time instructor of English language, I can confirm that the range and diversity of technologies that are generally used with adult learners differ from that used for young learners and kids. What I have found through years of teaching English is that it isn't always the case that new technologies replaced the old ones. Sometimes, when a novel technology is not continuously accessible, what motivates teachers' selections are the requirements for the lesson and the apparent necessities of student learners. Traditionally, for younger English language learners, effective classroom approaches usually consists of the use of songs, poems, and old stories along with recurrent language structures. Therefore, one may use the internet and the world-wide web as an amusing and fine source of true verbal models by recorded songs, speaking electronic books with native English speakers, music and video clips that help language learners with pronunciation as well as acquisition and retention of new words. These tools can also support teachers who don't feel as self-assured with their own language skills.

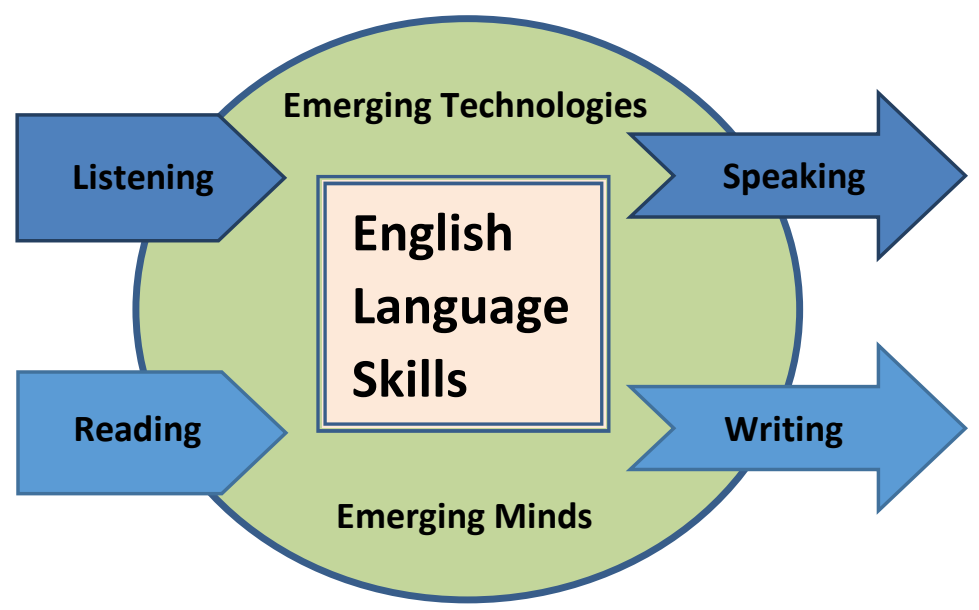

Figure 1.Fundamental English language skills and their interactions with emerging technologies. 
International Journal on Integrating Technology in Education (IJITE) Vol.5,No.1,March 2016

\subsection{Reading and Technology}

Reading is about understanding a written text by the learner. It is an important and complex input skill which requires perception and thought, and depends on the learner's vocabulary knowledge in the second language. During the reading process, the English language learner can advance his/her vocabulary bank and expressions, obtain new information and concepts, and improve his real-world knowledge. Successful reading is associated with two allied procedures: one being the vocabulary recognition (process of recognizing how written symbols correspond to one's verbal language) and the other as comprehension (making sense of words, expressions, sentences and terminologies). Considering the English language learning procedure, acquisition and retention of vocabulary are identified to have a great impact on language proficiency whereas the deficiency in lexical knowledge has been reported as one of the main impediments in successful communication [12-14]. English readers typically utilize their background knowledge like: words and terminologies, sentence structure knowledge, experience with text and other patterns to help them understand a written manuscript [22-23].There are several methods to develop and enhance the reading skill of the ESL/EFL learners by current and novel/emerging technologies, some of which are as follows:

- Practice Reading by Computers\& Multimedia Programs: Computer based reading software programs have been developed in recent years to enhance vocabulary and comprehension skills of learners via easy to understand texts. As a result, English language learners can have more interaction with texts in accordance to their individual needs and can ultimately improve their reading abilities. These user friendly computer programs can help students gradually move from easy to more difficult reading assignments, simulate tests and readily correct their answers. In addition, Multimedia softwares are being developed which utilize a mixture of text, computer graphics, animation, sound, and video clips to increase learner's motivation to enhance their vocabulary and reading skills. Digital texts and electronic books (e-books), particularly when accessed and jointly practiced on cool technologies like social robots and/or portable modern devices such as smart phones, tablets, and kindle e-readers, can inspire children and younger earners to read [12-14].

- Practice Reading by the Internet Browsing: Indeed, as a modern technological tool, using the Internet has a positive effect on English language learners to develop their general reading ability. Additionally, there exist many web sites organized exclusively to enrich the reading capabilities of EFL/ESL/ESP learners. A vast number of resources are also readily available to browse and read in the form of reports and newsletters, newspapers, magazines, journals, electronic libraries, online and electronic dictionaries, and encyclopedias which will noticeably improve the learner's vocabulary and reading skills.

\subsection{Listening and Technology}

Listening as one of the main skills in second language education, is the ability to recognize and comprehend what others are saying. The ability to understand a speaker's pronunciation, accent, grammar, vocabulary, and conception of meaning are the main features of listening. Hence, a 
International Journal on Integrating Technology in Education (IJITE) Vol.5,No.1,March 2016

capable good listener should be able to perform these four functions concurrently. Additionally, through listening learners at all age groups advance a large share of their information, education, and understanding of the environment surrounding them. The most significant features in EFL listening are [24]:

- To cope with redundancy, noise and the sounds,

- To understand accent, dialect, pitch, and anxiety,

- To guess and predict,

- To understand conversational and informal terminology,

- Exhaustion and Fatigue

- To use graphical and environmental signs.

There are several ways to improve the above features and enhance the listening capability of the ESL/EFL students using current and emerging technologies, some of which are listed as follows:

- Listening Practice by Tape-Recorders/CD Players: Tape-Recorders are one of the oldest technological listening tools, and their use has rapidly decreased in recent years due to the advancement of audio devices, CD players, and digital media recorders and players.

- Listening Practice by Computers: Computers have been used in recent years to provide students with visual and voice inputs in order to enhance their information and thoughts, and develop their listening skills. Using computer-based listening tests and learning video clips are significant in strengthening the understanding skills of the listener. Also, voice chatting through the Internet using the English language may also aid the communication competencies of the student learner.

- Listening Practice by Broadcasting: Listening to TV and radio English language learning programs, news on satellite TV channels, and songs is another way for developing the understanding ability through technology. However, searching and selecting for suitable specific programs compatible with the learners' needs is advised.

- Listening Practice by Robots: Robot Assisted Language Learning (RALL) is a new and emerging area in second language acquisition among young English learners [1214, 25-27]. Social robots as teaching assistant, story tellers, game partners, and educators can help to improve the listening ability of children and young EFL/ESL learners. They can talk like native English speakers with various accents and form repeated conversations and question and answer sessions with human learners without getting bored or tired.

\subsection{Writing and Technology}

Writing proficiency is frequently observed as the most difficult English language skill for EFL/ESL learners since they must engage in tasks like generating initial thoughts, forming structure, and perfectly apply grammar and vocabulary. To perform this task successfully, one should not ignore the close association and interdependency of reading and writing skills. As a simple notion, good readers do have a better chance of becoming better writers. Some of the 
International Journal on Integrating Technology in Education (IJITE) Vol.5,No.1,March 2016

modern technologies and approaches that are frequently used to develop writing skills for EFL/ESL learners are as follows:

- Writing Practice by Computers: Computers and office software/programs can be used to enhance the writing skills of English language learners. Writing statements, paragraphs, and reports in a foreign language can be very challenging for the EFL/ESL students. Graphics-based computer programs are developed to make the writing task much easier and fun, making student learners express their ideas more clearly. Learner's grammar and spelling skills can also be improved with the aid of advanced word processing programs. Hence, using computers as a tool in studying grammar and spelling is much more inspiring for the student than the traditional writing process with a paper and a pencil [28].

- Writing Practice by Text-Chatting: Text chatting through Mobile Assisted Language Learning (MALL) is another important technological approach using tablets or smart mobile phones to develop and enhance writing ability. This method offers the EFL learners a chance to practice writing on-the-move. It further provides an on-line and quick tool to write and share ideas, thoughts, and correspond instantly with the person on the other side [16-19].

- Writing Practice by Emails: Electronic mail is a modern method of writing and conveying messages through the internet. Using e-mails can be very effective for learners to improve their writing skills. Learners can use E-mails to learn how to formally respond to the incoming messages using meaningful language and statements.

- Writing and Calligraphy Practice by Robots and Haptics Devices: Social robots and modern haptic devices have also been used in recent years as a complimentary skill for teaching and training language calligraphy and writing styles [13, 29-30]. A feature that can certainly improve and beautify hand writing abilities and skills in many languages.

\subsection{Speaking and Technology}

Within an educational setting, some countries have decided that the formation of a well-educated, English speaking staff and workforce can be one way out of the current global economic decline. Consequently, in many countries children now begin speaking English at the primary level [3, 28, 31, and 33]. However, successful mutual human interaction and communication can take place between the speaker and the listener if and only if they understand each other. Hence, in simple terms, both speaker and listener have an affirmative task to accomplish. The speaker has to convert his/her message into verbal language and the listener has to understand the speaker's language. Introducing technology into learning English language speaking can appear in several forms as briefly specified in the following subsections.

- Speaking Practice by Video Conferencing: Video conferencing is currently a usual practice for enhancing verbal English language skills and understanding of culture. This is a highly economic and efficient way of inviting visitors into classrooms and/or enabling learners to cooperate with each other from a distance. In certain situations this 
International Journal on Integrating Technology in Education (IJITE) Vol.5,No.1,March 2016

method may be used to expose learners to native English speakers and/or to facilitate cultural exchanges. Today, some learners occasionally perform this task through Skype or other similar platforms on the internet.

- Speaking Practice by Internet Voice Chatting: Voice chatting via internet is a way for verbal interface and communication among the speaker and the listener. This method can also be truly valuable to the learner specially if the other person is a native English language speaker.

- Speaking Practice by Speech Synthesis Programs: Using artificial intelligence techniques, modern computer software and programs are developed to generate and/or model voice and vocal signals and decode human sound. These computer programs are known to act as a useful tool for improving the speaking ability of the learners. Practicing with such programs will strengthen the learners' vocabulary and pronunciation skills.

- Speaking Practice by Social Robots: Social humanoid and animal-like robots have been used through RALL strategies in recent years in classrooms in a few non-English speaking countries in order to motivate and engage young EFL/ESL learners to participate in conversation practices[12-14, 24, 26]. With the presence of a human instructor, these robots once programmed for various purposes and scenarios, create a fun and memorable learning environment by acting as teaching assistants, story tellers, game partners, performers, and educators. This novel method is proven to be very effective in improving the oral language skills of the young EFL/ESL learners.

- Speaking Practice by Mobile Games: In recent years, along with the advancement of technology, novel English learning materials have been developed by some companies for smart mobile phones and tablets. The subjects of these games are structured into themes related to reading and writing, English culture, spelling, word connotations, featuring exercises for practicing vocabulary; listening; speaking; and grammar. Additionally, using powerful multimedia systems, the software program presents gamebased activities to the user, records improvement and manually uploads successes at regular intervals to the company's servers [3].

Some of the main modern technologies generally applied to develop and improve the fundamental skills in English language learning are summarized and presented in Table 1. 
International Journal on Integrating Technology in Education (IJITE) Vol.5,No.1,March 2016

Table 1.A number of modern technologies that are commonly used in and outside the classroom to enhance the main English communication skills.

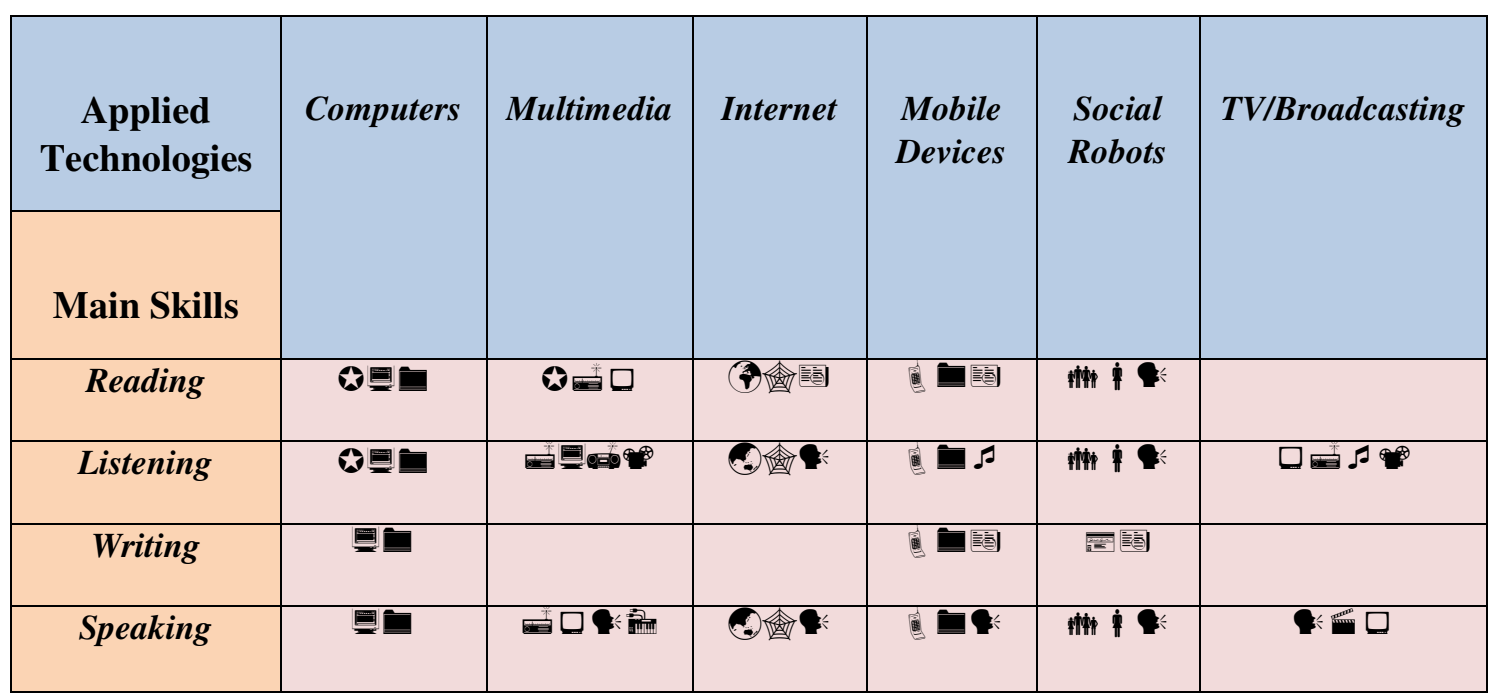

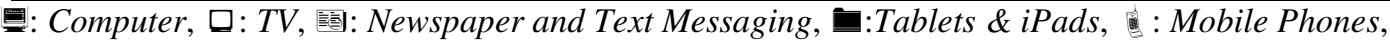

S: Voice Chatting, : Multimedia Devices, 0 : Internet and www, :

As shown, Figure 2 displays the learning cycle for language acquisition discussed earlier. It is worth noting that, the diagram depicts when our objective is to learn a foreign language, ability to read comes first, and based on that we learn how to write. As a result, on the foundation of the words and grammar learned through reading and writing, we have a better chance to be successful in listening, and finally the knowledge gained in the preceding steps will assist us to speak and communicate. In all of these steps we need to evaluate our skills in order to accomplish our objectives.

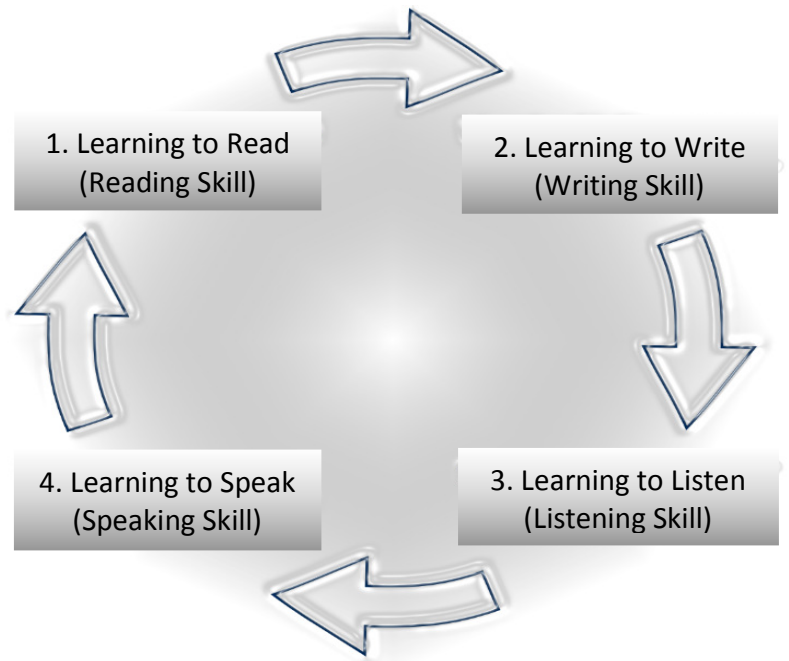

Figure 2. The language learning cycle. 
The assessments procedures can be varied in both skills they focus on and the way they are executed. These may be grammar tests, readings, blogging, recordings, individual or group work writing, and speaking. The technological tools described above have proven to be useful in assessments and providing feedbacks to EFL/ESP learners.

\section{English for Academic Purposes(EAP) ANd Technology}

English for Academic Purposes (EAP) is commonly considered as one of the two divisions of the greater field of English for Specific Purposes (ESP).The other division is English for Occupational Purposes (EOP). Recent demand-based viewpoint and investigation in EAP clearly indicates that, besides linguistic necessities, many of our academic responsibilities in educational settings involve basic familiarity with the use of new and emerging technologies. Faculty and students are anticipated to produce word-processed documents and reports, power-point slide presentations, use email services to communicate, access and contribute in online learning platforms, and conduct research using online electronic libraries and databases on the internet. With the appearance of new technologies, these expectations are rapidly growing. To be on the forefront of our field, EFL, ESP, and EAP practitioners should think ahead and recognize that it is necessary for their students to develop technology related knowledge and skills as part of their study in English language teaching and learning [31].Students and faculty who are currently able to operate efficiently, effectively, and appropriately in academic contexts need an additional element, and that is being able to function in an electronic environment. Such environments have gradually become a ubiquitous feature at many institutions of higher education across the world. In this respect, using technology to help academic trainings can be viewed as part of the study skills for EAP learners, and in support of universal language teaching and learning. Currently, using up-to-date technologies help EAP learners to build precise linguistic knowledge through indexes, improve and examine e-literacy skills, improve hands-on webpage searching and assessment practices, contribute and construct the significant cultural knowledge necessary for participating as members of the broader societies in which they are living [31]. Furthermore, internet-based Learning Management Systems (LMS) presents how flexible learning opportunities can be delivered when learners see limited class time in intensive courses and/or programs.

\section{English for Political Purposes(EPP) And Technology}

English for politicians or political purposes (EPP) has a worldwide application now a days. For politicians and government officials whether being native English speakers or when English is their second language, it is essential to constantly enhance their spoken English skills. They need to specifically improve their English language skills in terms of "adequate speed and accuracy" so that they are able to talk without ambiguity and anxiety for the listener in circumstances where they are trying to clarify their political position on current topics and subjects, to describe their personal thoughts, to debate problems at a high conceptual level, to respond to queries by journalists or reporters, and to take part in international conferences and interviews [3]. Some of the politician's summits are frequently in the form of teleconferences with interviews being conducted on the telephone or other virtual audio/video tools, which are then streamed on radio 
and/or television. Hence, to enhance their speaking skills and considering their busy schedule, online face-to-face instruction and practices are required through Skype sessions or by other technological means (telephone and audio/video interviews, teleconferencing, etc.) exposing them to different English accents with various teaching approaches. Materials and technology used may come from internet news channels like CNN, BBC or the English online version of other news channels to provide reliable and authentic content. The EPP learner oversees the topics and issues, which always circle around current political matters. Moreover, the text chat function can be used as a protocol to record improvements and feedback by an instructor. These are made at the same time as the politician learner is giving an interview or a speech, and then it will be used to discuss the session subsequently with him/her. Sometimes, this function is used to provide written reminders and prompts when a learner is searching for specific words or terms while speaking and thus simulates a teleprompter [32].

\section{CONCLUSION}

Whether we like technology or not, as EFL/ESP practitioners and instructors we can no longer afford not to integrate technology into our courses and classrooms. It is a $21^{\text {st }}$ century fact that technology in all forms plays an important role in learners' daily lives and professional activities. Therefore, our students and learners need digital and electronic literacy skills to connect internationally using diverse and up-to-date media tools, and to become independent EFL/ESL learners who can sustain with the dynamically changing professional world. In addition, using modern technologies to improve second language learning permits increased learner independence, providing him/her a more student-centered pedagogy with themselves being at the center of the learning process and more actively engaged in the learning than in traditional direct instruction methods [34].Many teachers nowadays are self-directing themselves when it comes to using technology, and are increasingly turning to online communities to learn how to implement technological tools in language instruction. This paper has briefly reviewed how technology in various forms can be applied in developing and enhancing the main language skills of the EFL/ESL/ESP/EAP/EPP learners. When it comes to ESP/EAP/EPP, based on previously reported studies one can conclude that using modern technology not only makes the language learning process more effective and efficient, but also offers tools that can readily simulate real-life work situations, while giving learners the chance to obtain and practice important $21^{\text {st }}$ century specialized and professional skills. The roles that modern technologies like CALL, MALL, RALL, Internet, social Multimedia, and other smart tools or devices currently play in language teaching and learning are making a significant and important contribution to the development of the field [33-38]. Consequently, the present study provides new insights into the use of technology in the EFL/ESL language classroom, suggesting that teachers and material developers should integrate diverse technology into the language learning process. This study has also some implications for technology-based education, language teaching, and social and cognitive robotics fields. 
International Journal on Integrating Technology in Education (IJITE) Vol.5,No.1,March 2016

\section{ACKNOWLEDMENT}

This work was supported in part by the National Elites Foundation of Iran (www.bmn.ir) during my first year at Islamic Azad University, Tehran-west Branch as an Assistant Professor of Applied Linguistics.

\section{REFECRENCES}

[1] Crystal, D. (1997). English as a global language. Cambridge: Cambridge University Press.

[2] Battro, AM. (2004). Digital skills, globalization and education, in Suárez-Orozco, M and QinHilliard,

D Globalization: Culture and Education in the New Millenium. University of California Press.

[3] Chris, P. (2013). Emerging technologies, emerging minds: digital innovations within the primary sector, pp. 17-42, Innovations in learning technologies for English language teaching,Edited by: Gary Motteram, British Council 2013 Series, www.britishcouncil.org

[4] Mawer, K., Stanley, G. (2011). Digital Play: Computer games and language aims. Peaslake: DELTA Publishing.

[5] Ramirez, L. (2010). Empower English language learners with tools from the web.London: Corwin.

[6] Terrell, SS. (2011). Integrating online tools to motivate young English language learners to practice English outside the classroom. International Journal of Computer-Assisted Language Learning and Teaching (IJCALLT) 1/2: 16-24.

[7] Warschauer, M. (2003). Technology and Social Inclusion: Rethinking the Digital Divide. Cambridge, MA: MIT Press.

[8] Wegerif, R. (2004). The Role of ICT as catalyst and support for dialogue. NALDIC Quarterly 1/4: 412.

[9] Whyte, S. (2011). Learning to teach with videoconferencing in primary foreign language classrooms. ReCALL 23/3: 271-293.

[10] Woo, M., Chu, S., Ho, A., Li, X. (2011). Using a wiki to scaffold primary-school students' collaborative writing. Educational Technology \& Society 14/1: 43-54.

[11] Zheng, D., Young, MF., Wagner, MM., Brewer, RA. (2009). Negotiation for action: English language learning in game-based virtual worlds. The Modern Language Journal93: 489-511.

[12] Meghdari, A., Alemi, M., Ghazisaedy, M., Taheri, A.R., Karimian, A., Zandvakili, M. (2013). Applying Robots as Teaching Assistant in EFL Classes at Iranian Middle-Schools, Proc. of the Int. Conf. on Education and Modern Educational Technologies (EMET-2013), Venice, Italy.

[13] Alemi, M., Meghdari, A., Ghazisaedy, M. (2014). Employing Humanoid Robots for Teaching English Language in Iranian Junior High-Schools, Int. Journal of Humanoid Robotics, Vol. 11, No. 3.

[14] Alemi, M., Meghdari, A., Ghazisaedy, M. (2015). The Impact of Social Robotics on L2 Learners' Anxiety and Attitude in English Vocabulary Acquisition, Int. Journal of Social Robotics, Vol. 7, No. 4, pp. 523-535.

[15] Singhal, M. (1997). The internet and foreign language education: Benefits and challenges. The Internet TESL Journal, 3(6). Retrieved from http://iteslj.org/Articles/Singhal-Internet.html

[16] Alemi, M., Lari, Z. (2012). SMS Vocabulary Learning: A Tool to Promote Reading Comprehension in L2, Int. Journal of Linguistics, 4 (4), pp. 275-287.

[17] Alemi, M., Anani S. R., Lari, Z., (2012). Successful Learning of Academic Word List via MALL: Mobile Assisted Language Learning, Int. Education Study Journal, 5 (6). 
International Journal on Integrating Technology in Education (IJITE) Vol.5,No.1,March 2016

[18] Alemi, M., Pashmforoosh, R., (2013). What is Facilitating Long-term Retention of Vocabulary: Computer-assisted, Mobile-based, or Dictionary, Proc. Current Trends in ELT: Putting the Learner in the Spotlight, Urmia University, Urumia, Iran.

[19] Alemi,M., (2013). MALL, Vocabulary and Reading: a Case of University Students, Proc. SMART Media in Academia: Research and Teaching Conf., Bacau, Romania.

[20] Read, J. (2004). Research in Teaching Vocabulary, Annual Review of Applied Linguistics, 24 (1), pp. 146-161.

[21] Sharma, P. (2009). Controversies in using technology in language teaching. Retrieved from http://www.teachingenglish.org.uk/articles/controversies-using-technology-language-teaching

[22] Pang, E.S., Muaka, A., Bernhardt, E. B., Kamil, M.L. (2010). Teaching Reading, http://www.ibe.unesco.org/publications/EducationalPracticesSeriesPdf/prac12e.pdf.

[23] Schmitt, N. (2000), "Vocabulary in Language Teaching", UK: Cambridge University Press.

[24] Saricoban, A. (1999). The teaching of listening. The Internet TESL Journal, 5(12). Retrieved from http://iteslj.org/Articles/Saricoban-Listening.html

[25] Alemi, M., Meghdari, A., Mahboub Basiri, N., Taheri, A. (2015). The Effect of Applying Humanoid Robots as Teacher Assistants to Help Iranian Autistic Pupils Learn English as a Foreign Language. Proc. of the 7th Int. Conference on Social Robotics, Paris, France.

[26] Meghdari, A., Alemi, M. (2015). Excerpts from socio-cognitive robotics. Proc. of the Symposium on Ports of Entry to the Field of Cognitive Sciences, Razi Int. Convention Center, Tehran, Iran.

[27] Saffari, E., Meghdari, A., Vazirnezhad, B., Alemi, M. (2015). Ava (A Social Robot): Design and Performance of a Robotic Hearing Apparatus, Proc. of the 7th Int. Conference on Social Robotics, Paris, France.

[28] Ybarra, R., Green T. (2003). Using technology to help ESL/EFL students develop language skills. The Internet TESL Journal, 9(3). http://iteslj.org/Articles/Ybarra-Technology.html

[29] Mansouri Boroujeni, M. (2009). Haptic Device Application in Virtual Training and Persian Calligraphy, M.Sc. Thesis, 01/2009, School of Science \& Engineering, Mechatronics Division, Sharif University of Technology-International Campus, Kish Island, Persian Gulf, Iran.

[30] Mansouri Boroujeni, M., Meghdari, A. (2009). Haptic Device Application in Persian Calligraphy", Proc. of the IEEE Int. Conference on Computer and Automation Engineering", pp. 160-164, Taiwan.

[31] Gilbert, J. (2013). English for Academic Purposes, pp. 119-144, Innovations in learning technologies for English language teaching, Edited by: Gary Motteram, British Council 2013 Series, www.britishcouncil.org

[32] Kern, N. (2013). Technology-integrated English for Specific Purposes lessons: real-life language, tasks, and tools for professionals, pp. 89-115, Innovations in learning technologies for English language teaching, Edited by: Gary Motteram, British Council 2013 Series, www.britishcouncil.org

[33] Nomass, B. B. (2013).The Impact of Using Technology in Teaching English as a SecondLanguage, English Language and Literature Studies; Vol. 3, No. 1, pp. 111-116.

[34] Jewell, M. (2006). Real-world contexts, skills and service learning for secondaryschool language learners', in Hanson-Smith, E. and Rilling, S. (editors) Learning languagesthrough technology. Alexandria, VA: TESOL.

[35] Meghdari, A., Alemi, M. (2015). Socio-Cognitive Robotics: Mysteries and Needs, Proc. of the 1st Int. ad 4th National ISEE Conf. on Engineering Education, Shiraz, Iran.

[36] Alemi, M. (2016). The Role of Technical English Language on Modern Engineering Education, Iranian Journal of Engineering Education, Vol. 18, No. 9, Spring 2016.

[37] Alemi, M., Meghdari, A. (2015), Technical English for Mechanical Engineers (TEME), 1st Edition, Sharif University of Technology Press. Tehran, Iran.

[38] Alemi, M., Farzaneh, F. (2016), Technical English for Electrical Engineers (TEEE), 1st Edition, Sharif University of Technology Press. Tehran, Iran. 
International Journal on Integrating Technology in Education (IJITE) Vol.5,No.1,March 2016

\section{Author}

Minoo Alemi is Assistant Professor and Division Head of Applied Linguistics at Islamic Azad University, Tehran-west Branch. She received her Ph.D. in Applied Linguistics (TEFL) from Allameh Tabataba'i University in 2011. She is the founder of RobotAssisted Language Learning (RALL), and the co-founder of Social Robotics in Iran which she achieved as a Post-Doctoral research associate in Sharif University of Technology. Her areas of interest are: discourse analysis, interlanguage pragmatics,

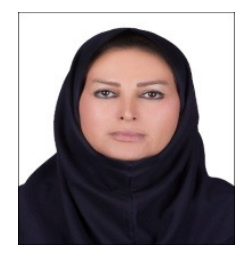
materials development, ESP, and RALL. Dr. Alemi has been the recipient of various teaching and research awards from Sharif University of Technology, Allameh Tabataba'i University, Islamic Azad University, and Int. Conf. on Social Robotics (ICSR2014). Thus far, she has presented and published over 70 papers and books in ELT. 